\title{
Prediction of sinus rhythm in patients undergoing concomitant Cox maze procedure through a median sternotomy
}

\author{
Niv Ad, MD, and Sari D. Holmes, PhD
}

\begin{abstract}
Objective: One of the challenges that exists when discussing the Cox maze procedure for atrial fibrillation (AF) with patients is predicting the success for a given patient. The purpose of the present study was to develop a scoring system using well-established clinical factors to predict the probability of sinus rhythm (SR) after surgery.

Methods: The data from patients 1 and 2 years postoperatively were analyzed using logistic regression to predict $\mathrm{SR}$, including the most accepted variables associated with failure (age, left atrium size, AF duration, AF type). Regression models were applied using hypothetical patients to examine the predicted probability of SR.

Results: The predictors of 1-year SR were a shorter AF duration and greater surgeon experience performing surgical ablation. The predictors at 2 years were a shorter AF duration and smaller left atrium. The 1-year prediction model applied to hypothetical data found a $1-\mathrm{cm}$ increase in left atrial size associated with a $0.4 \%$ reduction in SR probability, a 5-year increase in AF duration associated with a $0.8 \%$ reduction, and a reduction by 50 cases of surgeon experience associated with a $1.0 \%$ reduction. The 2-year model found a $1-\mathrm{cm}$ increase in left atrial size associated with a 1.0\% reduction in SR probability, a 5-year increase in AF duration associated with a $0.8 \%$ reduction, and a reduction by 50 cases of experience associated with a $0.2 \%$ reduction.
\end{abstract}

Conclusions: Our findings are the first step in establishing a risk scoring system to better predict the outcomes after surgical ablation for AF and improve the ability to discuss the risk and benefits with patients. ( $\mathrm{J}$ Thorac Cardiovasc Surg 2014;148:881-7)

Since its introduction and refinement during recent decades, the Cox maze procedure for surgical ablation of atrial fibrillation (AF) has become the reference standard for the surgical treatment of $\mathrm{AF}^{1,2}$ The overall freedom from symptomatic $\mathrm{AF}$ and restoration of sinus rhythm (SR) after the Cox maze procedure has been high in reported studies. $^{3-5}$

Several well-established clinical variables have been associated with failure of the Cox maze procedure..$^{6-8}$ However, despite the significant progress associated with advanced surgical ablation technology and wellestablished guidelines, the field still lacks reliable risk prediction models to improve patient selection for surgical ablation and help predict the efficacy of the procedure. ${ }^{8,9}$ The most acceptable variables associated with surgical ablation for AF outcome have been age, left atrial (LA) size, type and duration of $\mathrm{AF}$, and the number of concomitant procedures. ${ }^{10-13}$

\footnotetext{
From the Department of Cardiac Surgery, Inova Heart and Vascular Institute, Falls Church, Va.

Disclosures: Niv Ad reports consulting and lecture fees from Atricure, Medtronic, and Estech. The other author has nothing to disclose with regard to commercial support. Read at the 94th Annual Meeting of The American Association for Thoracic Surgery, Toronto, Ontario Canada, April 26-30, 2014.

Received for publication April 9, 2014; revisions received April 16, 2014; accepted for publication April 18, 2014; available ahead of print July 18, 2014

Address for reprints: Niv Ad, MD, Department of Cardiac Surgery, Inova Heart and Vascular Institute, 3300 Gallows Rd, Suite 3100, Falls Church, VA 22042 (E-mail: Niv.Ad@inova.org).

$0022-5223 / \$ 36.00$

Copyright (C) 2014 by The American Association for Thoracic Surgery http://dx.doi.org/10.1016/j.jtcvs.2014.04.050
}

In the present study, we examined data that had been prospectively collected from patients who had undergone the Cox maze III or IV procedure for AF ablation concomitantly with other cardiac procedures through a midsternotomy. The study purpose was to develop a risk scoring platform to predict the probability of SR at 1 and 2 years after the Cox maze procedure that could be applied in an informative manner to a larger group of patients.

\section{METHODS}

The full concomitant Cox maze III or IV was performed in 501 consecutive patients by way of a median sternotomy at a single center from January 2005 to October 2013. Our institutional review board approved the present study (approval nos. 06.022 and 12.055). Data regarding clinical events, medication, and rhythm status were collected prospectively before and after surgery, and follow-up data were collected at 3, 6, 9, 12, 18 , and 24 months postoperatively and annually thereafter. Rhythm status was verified by electrocardiography and 24-hour Holter monitoring at each follow-up point for all patients. The Heart Rhythm Society (HRS) definition of failure (all documented atrial arrhythmias lasting $>30$ seconds) was used to determine the return to SR. ${ }^{14}$ In the present study, the endpoint of rhythm status was captured without consideration of antiarrhythmic drug treatment. The data collected using our local surgical ablation registry were merged with data from our local Society of Thoracic Surgeons database. At 1 year postoperatively, 303 patients were available for the analyses with complete follow-up data, and at 2 years, 195 patients were available for the analyses.

\section{Operative Approach}

The Cox maze procedure III or IV was performed by multiple surgeons, as previously described. ${ }^{15,16}$ The LA appendage was managed at the surgeon's discretion in all patients using either excision or exclusion (surgically, AtriClip, or multiple endoloops). Appropriate control of the 


$$
\begin{aligned}
& \text { Abbreviations and Acronyms } \\
& \text { AF }=\text { atrial fibrillation } \\
& \text { AUC }=\text { area under the curve } \\
& \text { CI }=\text { confidence interval } \\
& \text { HRS }=\text { Heart Rhythm Society } \\
& \text { LA }=\text { left atrial } \\
& \text { OR }=\text { odds ratio } \\
& \text { SR }=\text { sinus rhythm }
\end{aligned}
$$

LA appendage was confirmed by echocardiography in all patients. The ablative energy source used for the Cox maze procedure was cryothermia alone (Medtronic, Minneapolis, Minn) in $56 \%$ of the patients and a combination of bipolar radiofrequency and cryothermia (AtriCure, Cincinnati, Ohio) in $44 \%$ of the patients.

\section{Statistical Analysis}

All analyses were conducted using the Statistical Package for the Social Sciences, version 17.0 (SPSS Inc, Chicago, Ill), and 2-tailed $P$ values were used. Continuous data are presented as the mean \pm standard deviation or median and interquartile range, and categorical data are presented as frequencies and percentages, unless otherwise noted. Group comparisons for categorical variables were conducted with the chi-square test or Fisher's exact test, and comparisons for continuous variables were conducted using Student's $t$ test or the Mann-Whitney $U$ test based on test assumption requirements. Multivariate logistic regression was used to determine the prediction model for SR at 1 and 2 years postoperatively and included the following factors determined a priori: age, gender, preoperative LA size $(\mathrm{cm})$, duration of AF before surgery, AF type, number of concomitant surgical procedures, and surgeon experience in surgical ablation. The number of concomitant surgical procedures was operationally defined as the total additive number of any surgical procedures performed concomitantly with the Cox maze procedure. Surgeon experience (continuous measure) was defined as the number of surgical ablation procedures the patient's surgeon had performed before their surgery and then scaled by 10 for use in the multivariate model. After obtaining the coefficients for each logistic regression model, internal validation of the prediction models was conducted using ordinary nonparametric bootstrapping with 999 bootstrap samples and bias-corrected, accelerated $95 \%$ confidence intervals (CIs). Receiver operating characteristic curves were constructed for both 1- and 2-year models, and bootstrapping with 999 samples was performed to evaluate the reliability of the area under the curve (AUC) for each model. In addition, hypothetical patients were evaluated using the prediction models to determine the effect that changes in the predictor factors would have on the probability for SR.

The prediction models were then applied to all patients with complete predictor variable data $(\mathrm{n}=439$; LA size missing, $\mathrm{n}=32$; AF duration missing, $n=30$ ), even those without observed rhythm status information, to determine the predicted probability of SR rhythm at each follow-up point. Patients at the high and low end of individual predictor variables from the model were examined with respect to predicted probability of SR from the 1- and 2-year models. For continuous factors (ie, age, LA size, duration of $\mathrm{AF}$ ), tertiles were created, and the lowest and highest tertile groups were compared for the predicted probability of SR.

\section{RESULTS}

The clinical characteristics of the patients available for the analyses at 1 and 2 years after concomitant Cox maze surgery are listed in Table 1 . The mean patient age was 66 years, and approximately $60 \%$ of patients were male at both measurement points. The surgeon experience for these patients ranged from 1 case to $>250$ cases. The preoperative and surgical factors remained similar in the 1- and 2-year samples, given the overlap in patients between the 2. At 1 year, $92 \%$ of the patients ( 280 of 303 ) were in SR, and $90 \%$ were in SR and did not require class I or III antiarrhythmic medication. By 2 years, $90 \%$ of patients (175 of 195) were in SR, and $90 \%$ were in sinus rhythm and did not require antiarrhythmic medication.

\section{Multivariate Regression Analyses}

The significant independent predictors of 1-year SR were a shorter duration of AF in years (odds ratio [OR], 0.91; 95\% CI, 0.84-0.98; $P=.02$ ) and surgeon experience (OR, 1.12; 95\% CI, 1.06-1.19; $P<.001$; Table 2). The significant predictors of 2-year SR were a shorter duration of AF in years (OR, 0.88; 95\% CI, 0.79-0.99; $P=.03)$ and smaller LA size (OR, 0.49; 95\% CI, 0.26-0.90; $P=.02$ ). Internal validation of both logistic regression models was conducted using bootstrapping with 999 samples; the results are presented in Table 3. Almost all variables included in the model demonstrated robust results, with small $95 \%$ CIs around the original coefficients. The 2 dummy-coded variables that constituted the AF type appeared to be less reliable, with wider $95 \%$ CIs around the original coefficients. Evaluation of the 1-year prediction model with receiver operating characteristic curve analysis found an AUC of 0.858; however, bootstrapping revealed an AUC of 0.817 (95\% CI, 0.705-0.913). For the 2-year prediction model, the receiver operating characteristic curve analysis found an AUC of 0.859 , and bootstrapping revealed an AUC of 0.844 (95\% CI, 0.761-0.918).

\section{Application of Prediction Models}

These models can be applied to any patients with complete predictor variable data using 3 steps. First, one enters the patient's information into the appropriate boxes in Table 4 and multiplies each value by the weight for that variable. Second, one sums all weighted values with the constant in the appropriate column, which will provide the $\operatorname{logit}(P)$. Third, one enters the $\operatorname{logit}(P)$ value into the following equation to determine the predicted probability: $P=1 /\left[1+\mathrm{e}^{-\operatorname{logit}(P)}\right]$. Importantly, application of the 1 -year prediction model to a hypothetical typical patient (65-year-old, male patient with an LA size of $5.0 \mathrm{~cm}$ and 3 -year duration of persistent $\mathrm{AF}$ who underwent 1 concomitant procedure by a surgeon with 150 cases of experience) found a $98.6 \%$ probability of SR at 1 year and a $99.1 \%$ probability of SR at 2 years. Keeping all other parameters constant for the hypothetical patient, the 1-year prediction model found that a $1-\mathrm{cm}$ increase in LA size was associated with a $0.4 \%$ reduction, a 5-year increase in $\mathrm{AF}$ duration was associated with a $0.8 \%$ reduction, changing the $\mathrm{AF}$ type to 
TABLE 1. Patient characteristics for those with rhythm status at 1 and 2 years postoperatively

\begin{tabular}{lcc}
\hline \multicolumn{1}{c}{ Characteristic } & $\begin{array}{c}\text { Patients at } \\
\mathbf{1 ~}(\mathbf{n}=\mathbf{3 0 3})\end{array}$ & $\begin{array}{c}\text { Patients at } \\
\mathbf{2 ~ y}(\mathbf{n}=\mathbf{1 9 5})\end{array}$ \\
\hline Age (y) & $66.1 \pm 11.7$ & $65.8 \pm 11.7$ \\
Female gender & $128(42)$ & $82(42)$ \\
Ejection fraction (\%) & $54.7 \pm 11.7$ & $54.9 \pm 11.6$ \\
Congestive heart failure & $134(44)$ & $87(45)$ \\
Diabetes & $41(14)$ & $30(15)$ \\
Chronic pulmonary disease & $42(14)$ & $24(12)$ \\
Preoperative creatinine level & $1(0.8-1.1)$ & $1(0.8-1.2)$ \\
Peripheral vascular disease & $23(8)$ & $16(8)$ \\
Cerebrovascular disease & $33(11)$ & $20(10)$ \\
Previous CVA & $21(7)$ & $13(7)$ \\
Hypertension & $200(66)$ & $135(69)$ \\
Logistic EuroSCORE I (\%) & $8.1 \pm 8.4$ & $7.8 \pm 7.5$ \\
Left atrial size (cm) & $5.1 \pm 1.0$ & $5.2 \pm 0.9$ \\
AF type & & \\
$\quad$ Longstanding, persistent & $147(48.5)$ & $104(53)$ \\
Persistent & $121(40)$ & $74(38)$ \\
Paroxysmal & $35(11.5)$ & $17(9)$ \\
AF duration (mo) & $39.8 \pm 60.1$ & $37.4 \pm 50.2$ \\
Previous cardioversion & $101(33)$ & $66(34)$ \\
Previous ablation & $33(11)$ & $21(11)$ \\
Concomitant CABG* & $98(32)$ & $66(34)$ \\
Concomitant valve surgery* & $257(85)$ & $165(85)$ \\
Cardiopulmonary bypass time (min) & $178.4 \pm 50.7$ & $180.7 \pm 51.2$ \\
Crossclamp time (min) & $120.4 \pm 38.9$ & $123.5 \pm 37.5$ \\
\hline Data presented as n (\%), mean \pm standard deviation, or median (interquartile range) \\
CVA, Cerebrovascular accident; $A F$, atrial fibrillation; CABG, coronary artery bypass \\
grafting; EuroSCORE, European System for Cardiac Operative & Risk Evaluation. \\
*Categories not mutually exclusive. & & \\
& & \\
& &
\end{tabular}

longstanding persistent $\mathrm{AF}$ was associated with a $2.5 \%$ reduction, and a decrease of 50 cases in surgeon experience was associated with a $1.0 \%$ reduction in the predicted probability of SR at 1 year. Keeping the other parameters

TABLE 2. Results of multivariate logistic regression models predicting sinus rhythm at 1 and 2 years after Cox maze procedure

\begin{tabular}{|c|c|c|c|c|c|c|}
\hline \multirow[b]{2}{*}{ Variable } & \multicolumn{3}{|c|}{ 1-y SR* } & \multicolumn{3}{|c|}{ 2-y SR } \\
\hline & B & OR & $P$ value & B & OR & $P$ value \\
\hline Age & 0.005 & 1.01 & .83 & -0.021 & 0.98 & .41 \\
\hline Female gender & -0.013 & 0.99 & .98 & 0.348 & 1.42 & .55 \\
\hline LA size & -0.275 & 0.76 & .25 & -0.723 & 0.49 & .02 \\
\hline AF duration (y) & -0.093 & 0.91 & .02 & -0.125 & 0.88 & .03 \\
\hline \multicolumn{7}{|l|}{ AF type } \\
\hline Persistent vs paroxysmal & -0.260 & 0.77 & .84 & 1.664 & 5.28 & .26 \\
\hline $\begin{array}{l}\text { Longstanding vs } \\
\text { paroxysmal }\end{array}$ & -1.336 & 0.26 & .24 & -0.506 & 0.60 & .66 \\
\hline Surgeon experience & 0.114 & 1.12 & $<.001$ & 0.038 & 1.04 & .09 \\
\hline $\begin{array}{c}\text { Total concomitant } \\
\text { procedures }\end{array}$ & -0.648 & 0.52 & .08 & -0.607 & 0.55 & .10 \\
\hline Constant & 4.814 & & & 8.407 & & \\
\hline
\end{tabular}

constant, the 2-year prediction model found that a $1-\mathrm{cm}$ increase in LA size was associated with a $1.0 \%$ reduction, a 5-year increase in AF duration was associated with a $0.8 \%$ reduction, a change to longstanding persistent $\mathrm{AF}$ was associated with a $6.6 \%$ reduction, and a reduction of 50 cases of surgeon experience was associated with a $0.2 \%$ reduction in the predicted probability of SR at 2 years.

Applying the prediction model to an older patient (78-year-old man) with clinical characteristics similar to the typical patient described in the previous paragraph resulted in a $98.7 \%$ predicted probability of SR at 1 year and $98.8 \%$ predicted probability of SR at 2 years. Keeping all other factors constant, the effect of changing to a less experienced surgeon (10 total cases of experience) changed the results for this older patient to a $94.0 \%$ probability of SR at 1 year and $98.0 \%$ probability of SR at 2 years postoperatively.

After determining which patients were in the highest and lowest tertiles of continuous variables for all patients with complete predictor variable data $(n=439)$, the analyses indicated that the predicted probability of SR was significantly lower for those with the longest AF duration $(>3.2$ years) than for those with the shortest AF duration $(<0.37$ years $)$ at the 1 - and 2 -year points $(89 \%$ vs $97 \%$, $P<.001$; and $81 \%$ vs $98 \%, P<.001$, respectively; Figure 1). For the LA size tertile comparisons, the predicted probability of SR was significantly lower for patients with a larger LA size $(>5.5 \mathrm{~cm})$ than for those with a smaller LA size $(<4.6 \mathrm{~cm})$ at 2 years $(84 \%$ vs $96 \%, P<.001)$ but not at 1 year $(92 \%$ vs $94 \%, P=.08$; Figure 2$)$. In the oldest age tertile group ( $>72$ years), the predicted probability of SR was lower than in the youngest age tertile group $(<63$ years) at 2 years $(89 \%$ vs $94 \%, P<.001)$ but not at 1 year $(92 \%$ vs $94 \%, P=.27)$. The predicted probability of SR was greater for surgeons in the highest tertile of experience ( $>301$ cases) than for surgeons in the lowest tertile of experience ( $<62$ cases) at both 1 and 2 years after surgery (99.6\% vs $84 \%, P<.001$ and $94 \%$ vs $88 \%, P<.001$, respectively). No differences were seen by gender for the 1- or 2-year predicted probability of SR.

\section{DISCUSSION}

In the present large cohort study, we identified significant predictive models for the success of the Cox maze procedure performed concomitantly with other cardiac procedures. In these models, the significant predictors of SR were a shorter duration of $\mathrm{AF}$, a smaller LA size, and greater surgeon experience in performing surgical ablation. Once these prediction models for SR at 1 and 2 years after the Cox maze procedure undergo additional testing and validation, the prediction method can be applied to any patient with the necessary data points. These findings are the first step in establishing a risk scoring system that will allow better prediction of the rhythm outcome after surgical ablation 
TABLE 3. Internal validation of prediction models using nonparametric bootstrap technique

\begin{tabular}{|c|c|c|c|c|c|c|c|c|}
\hline \multirow[b]{2}{*}{ Variable } & \multicolumn{4}{|c|}{ 1-y SR } & \multicolumn{4}{|c|}{ 2-y SR } \\
\hline & Original & Bias & SE & $95 \%$ BCa CI & Original & Bias & SE & $95 \%$ BCa CI \\
\hline Age & 0.005 & -0.003 & 0.035 & -0.07 to 0.06 & -0.021 & -0.010 & 0.041 & -0.11 to 0.04 \\
\hline Female gender & -0.013 & 0.020 & 0.607 & -1.27 to 1.04 & 0.348 & 0.214 & 0.924 & -1.74 to 1.46 \\
\hline LA size & -0.275 & -0.027 & 0.337 & -0.91 to 0.48 & -0.723 & -0.116 & 0.507 & -1.54 to 0.41 \\
\hline AF duration & -0.093 & -0.013 & 0.048 & -0.17 to 0.02 & -0.125 & -0.030 & 0.084 & -0.27 to 0.03 \\
\hline \multicolumn{9}{|l|}{ AF type } \\
\hline Persistent vs paroxysmal & -0.260 & -5.399 & 8.010 & -16.10 to 18.11 & 1.664 & -0.030 & 11.016 & -15.40 to 19.27 \\
\hline LS persistent vs paroxysmal & -1.336 & -5.765 & 7.718 & -17.17 to 1.02 & -0.506 & -5.610 & 8.235 & -18.34 to 2.52 \\
\hline Surgeon experience & 0.114 & 0.021 & 0.059 & 0.04 to 0.19 & 0.038 & 0.006 & 0.032 & -0.02 to 0.10 \\
\hline Concomitant procedures & -0.648 & -0.053 & 0.487 & -1.61 to 0.28 & -0.607 & -0.022 & 0.529 & -1.64 to 0.49 \\
\hline Constant & 4.814 & 6.290 & 8.394 & -3.59 to 19.77 & 8.407 & 7.169 & 10.130 & -1.29 to 26.51 \\
\hline
\end{tabular}

$S R$, Sinus rhythm; $S E$, standard error; $B C a$, adjusted bootstrap confidence interval; $C I$, confidence interval; $L A$, left atrial; $A F$, atrial fibrillation; $L S$, longstanding.

of AF and will improve surgeons' ability to discuss the risks and benefits with their patients.

In recent years, multiple risk prediction models have been developed for patients undergoing cardiac surgery. These models have focused mainly on the operative and perioperative outcomes and the associated risk of morbidity and mortality after the surgical intervention. ${ }^{17-19}$ The availability of such risk models improved the ability of surgeons to communicate with patients and referring physicians about the predicted risk. Such risk models are also excellent tools for understanding the cost effectiveness across different approaches and new technologies, with the best example being the large US transcatheter valve studies.

The field of surgical ablation of AF using different surgical ablation devices is relatively new and faces significant challenges. It is well established that a lack of standardization exists with surgical ablation for AF in terms of the decision making to perform surgical ablation and incorrect perceptions regarding the risk and effectiveness of the procedure. $^{20,21}$ Just as important, different surgeons will apply different lesion sets and use different ablative devices in different situations, sometimes with inferior outcomes. ${ }^{22-24}$

TABLE 4. Sinus rhythm prediction model calculator

\begin{tabular}{|c|c|c|}
\hline & 1-y model & 2-y model \\
\hline Variable & $\begin{array}{c}\text { Coefficient } \\
\text { (B) } \times \text { value }\end{array}$ & $\begin{array}{l}\text { Coefficient } \\
(\text { B }) \times \text { value } \\
\end{array}$ \\
\hline Age (y) & $0.005 \times$ & $-0.021 \times$ \\
\hline Gender* & $-0.013 \times$ & $0.348 \times$ \\
\hline LA size $(\mathrm{cm})$ & $-0.275 \times$ & $-0.723 \times$ \\
\hline AF duration $(\mathrm{y})$ & $-0.093 \times$ & $-0.125 \times$ \\
\hline AF type $\mathrm{A} \dagger$ & $-0.260 \times$ & $1.664 \times$ \\
\hline AF type $\mathrm{B} \ddagger$ & $-1.336 \times$ & $-0.506 \times$ \\
\hline Surgeon experience $\S$ & $0.114 \times$ & $0.038 \times$ \\
\hline Concomitant procedures $\|$ & $-0.648 \times$ & $-0.607 \times$ \\
\hline Constant & 4.814 & 8.407 \\
\hline
\end{tabular}

*Male, enter 0 ; female, enter $1 . \dagger$ Paroxysmal, enter 0 ; persistent, enter 1 ; longstanding persistent, enter 0 . †ุParoxysmal, enter 0 ; persistent, enter 0 ; longstanding persistent, enter 1 . $\S$ Enter total number of surgical ablation cases previously performed by surgeon divided by 10. ||Enter total number of concomitant procedures, not including Cox maze procedure.
The Cox maze procedure has been considered the standard for surgical ablation for $\mathrm{AF}^{3}$ Since the first cut and sew procedure performed $>25$ years ago, a major shift in the surgical technique to apply the lesions has been made, and it is now being applied almost solely using surgical ablative tools, with rare exceptions. When done appropriately, the transition to ablative tools has been associated with success rates similar to those reported for the cut and sew procedure. ${ }^{25}$

The recent American Association for Thoracic Surgery survey revealed that a real gap exists between surgeons' perception and the real world data related to surgical ablation for $\mathrm{AF}^{21}$ Despite established, evidence-based guidelines and consensus statements, surgeons have been reluctant to perform surgical ablation concomitantly with other cardiac surgical procedures, mainly secondary to an incorrect perception of increased operative risk and lack of efficiency. ${ }^{9,14,20}$ Multiple recent publications have demonstrated the safety and improved long-term survival associated with surgical ablation for $\mathrm{AF}^{26-28}$ Therefore,

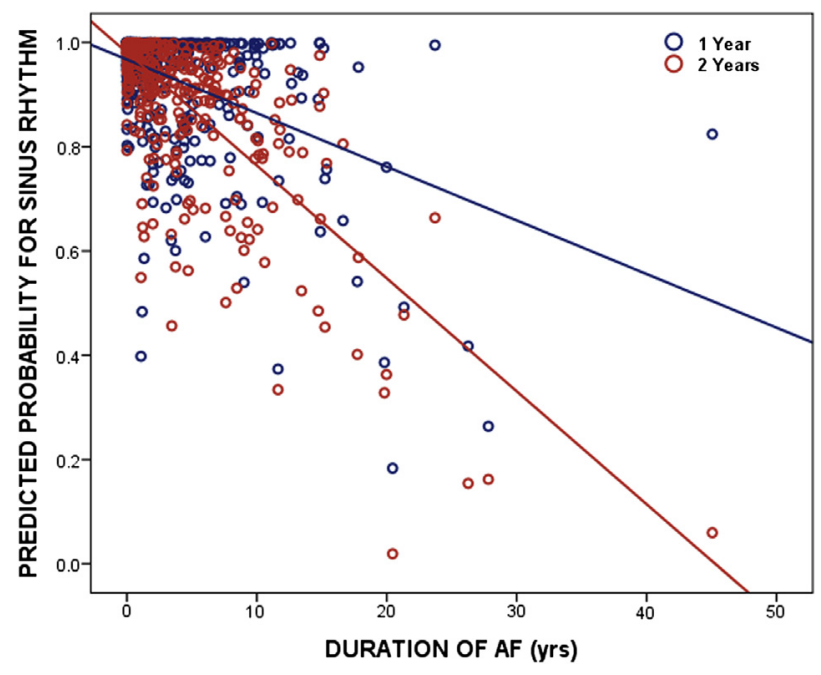

FIGURE 1. Predicted probability of sinus rhythm at 1 and 2 years stratified by duration of atrial fibrillation. $A F$, Atrial fibrillation. 


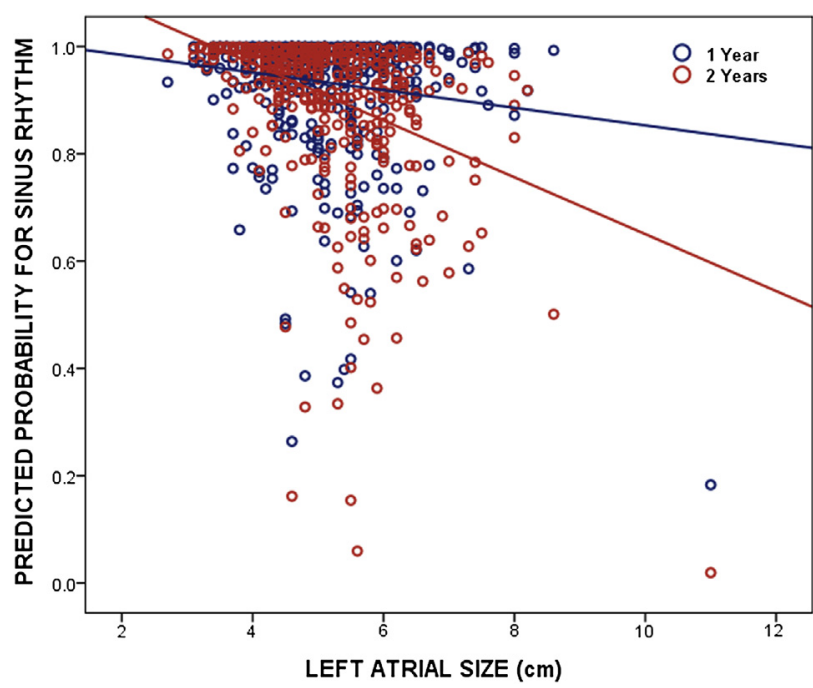

FIGURE 2. Predicted probability of sinus rhythm at 1 and 2 years stratified by left atrial size.

efforts should target education and training of surgeons in the essential nature of surgical ablation to improve delivery of care.

The prediction model we have presented is the first step in establishing a more universal model. To move forward from this first step, these rhythm prediction models will need to undergo external validation with larger patient cohorts from multiple centers. We were able to apply internal validation techniques to understand how likely these models will be replicable in future studies and at other centers. Bootstrapping techniques were applied and demonstrated that the coefficients obtained from these prediction models were quite robust. The type of AF was the 1 factor that the bootstrap results indicated might have limited repeatability in future work. Removal of the AF type from the models did not change which factors were significant predictors of SR. However, because of the clinical importance surrounding the type of AF, this variable was kept as a factor in these models despite some statistical limitations (ie, categorical variable, collinearity). Also, other studies have found a significant effect of the AF type on outcomes, and the choice of factors for the model had focused on including the most accepted predictors for SR after surgical ablation. ${ }^{11,29}$ In the real-world clinical setting where these prediction models could be used, the type of AF is an important clinical characteristic that can play a substantial role in surgical decision making.

\section{Study Limitations}

The main limitations of the present study involved the statistical shortcomings associated with attempting to predict outcomes in such a way that incorporates both previous research evidence and clinical considerations. As previously discussed, the inclusion of the AF type in the prediction models introduced ambiguity regarding the reproducibility of the effect of the AF type in future prediction models. Although overlap existed between factors such as the AF duration and the AF type, the collinearity in these models was not largely affected by inclusion of the AF type.

Another potential limitation of this model was that any type of concomitant procedure was counted equally in the analyses and therefore considered equally important in the prediction models. For example, it might be that the effect of a valve procedure differs from that of the addition of coronary artery bypass grafting. However, to answer this question, a much larger group of patients would be required.

Also, we chose to use the HRS definition of success, regardless of antiarrhythmic medication status. The main reason for this decision was the variability in antiarrhythmic medication management. Our center has strongly recommended that any patient who returns to SR, as verified by 24-hour Holter monitoring, should have their antiarrhythmic medications stopped by 6 months postoperatively. However, at any given point after Cox maze surgery, it is possible that patients truly in SR will continue to take antiarrhythmic medication despite their eligibility to stop the medication. Therefore, we believed that the prediction of a return to SR regardless of medication status represented a less biased outcome measure.

\section{CONCLUSIONS}

In the present study, we were able to establish what should be considered the first step in improving our ability to predict the rhythm outcome for the first 2 years after the Cox maze procedure when performed concomitantly through a median sternotomy. Applying this risk scoring system to potential patients could result in a much improved preoperative assessment and discussion related to the procedure.

The authors would like to acknowledge Deborah J. Shuman, Lori E. Stone, Lisa M. Martin, and Graciela Pritchard for their assistance in the preparation of our report.

\section{References}

1. Cox JL, Boineau JP, Schuessler RB, Ferguson TB Jr, Cain ME, Lindsay BD, et al. Successful surgical treatment of atrial fibrillation. review and clinical update. JAMA. 1991;266:1976-80.

2. Damiano RJ Jr, Gaynor SL, Bailey M, Prasad S, Cox JL, Boineau JP, et al. The long-term outcome of patients with coronary disease and atrial fibrillation undergoing the Cox maze procedure. J Thorac Cardiovasc Surg. 2003;126:2016-21.

3. Prasad SM, Maniar HS, Camillo CJ, Schuessler RB, Boineau JP, Sundt TM III, et al. The Cox maze III procedure for atrial fibrillation: long-term efficacy in patients undergoing lone versus concomitant procedures. J Thorac Cardiovasc Surg. 2003;126:1822-8.

4. Schaff HV, Dearani JA, Daly RC, Orszulak TA, Danielson GK. Cox-maze procedure for atrial fibrillation: Mayo clinic experience. Semin Thorac Cardiovasc Surg. 2000;12:30-7.

5. McCarthy PM, Gillinov AM, Castle L, Chung M, Cosgrove D III. The Cox-maze procedure: the Cleveland Clinic experience. Semin Thorac Cardiovasc Surg. 2000; $12: 25-9$. 
6. Gillinov AM, Sirak J, Blackstone EH, McCarthy PM, Rajeswaran J, Pettersson G, et al. The Cox maze procedure in mitral valve disease: predictors of recurrent atrial fibrillation. J Thorac Cardiovasc Surg. 2005;130:1653-60.

7. Saliba W, Wazni OM. Sinus rhythm restoration and treatment success: insight from recent clinical trials. Clin Cardiol. 2011;34:12-22.

8. Calkins H, Brugada J, Packer DL, Cappato R, Chen SA, Crijns HJ, et al. HRS/ EHRA/ECAS expert consensus statement on catheter and surgical ablation of atrial fibrillation: recommendations for personnel, policy, procedures and follow-up. A report of the Heart Rhythm Society (HRS) Task Force on catheter and surgical ablation of atrial fibrillation developed in partnership with the European Heart Rhythm Association (EHRA) and the European Cardiac Arrhythmia Society (ECAS); in collaboration with the American College of Cardiology (ACC), American Heart Association (AHA), and the Society of Thoracic Surgeons (STS). endorsed and approved by the governing bodies of the American College of Cardiology, the American Heart Association, the European Cardiac Arrhythmia Society, the European Heart Rhythm Association, the Society of Thoracic Surgeons, and the Heart Rhythm Society. Europace. 2007;9: 335-79.

9. Ad N, Cheng DC, Martin J, Berglin EE, Chang BC, Doukas G, et al. Surgical ablation for atrial fibrillation in cardiac surgery: a consensus statement of the International Society for Minimally Invasive Cardiothoracic Surgery (ISMICS) 2009. Innovations (Phila). 2010;5:74-83.

10. Gillinov AM, Bhavani S, Blackstone EH, Rajeswaran J, Svensson LG, Navia JL, et al. Surgery for permanent atrial fibrillation: impact of patient factors and lesion set. Ann Thorac Surg. 2006;82:502-13; discussion 513-4.

11. Pecha S, Schafer T, Subbotina I, Ahmadzade T, Reichenspurner H, Wagner FM. Rhythm outcome predictors after concomitant surgical ablation for atrial fibrillation: a 9-year, single-center experience. J Thorac Cardiovasc Surg. October 18, 2013 [Epub ahead of print].

12. Damiano RJ Jr, Badhwar V, Acker MA, Veeragandham RS, Kress DC, Robertson JO, et al. The CURE-AF trial: a prospective, multicenter trial of irrigated radiofrequency ablation for the treatment of persistent atrial fibrillation during concomitant cardiac surgery. Heart Rhythm. 2014;11:39-45.

13. Ad N, Holmes SD, Stone LE, Pritchard G, Henry L. Rhythm course over 5 years following surgical ablation for atrial fibrillation. Eur J Cardiothorac Surg. March 17, 2014 [Epub ahead of print].

14. Calkins H, Kuck KH, Cappato R, Brugada J, Camm AJ, Chen SA, et al. 2012 HRS/EHRA/ECAS expert consensus statement on catheter and surgical ablation of atrial fibrillation: recommendations for patient selection, procedural techniques, patient management and follow-up, definitions, endpoints, and research trial design. J Interv Card Electrophysiol. 2012;33:171-257.

15. Cox JL, Schuessler RB, D'Agostino HJJ, Stone CM, Chang BC, Cain ME, et al The surgical treatment of atrial fibrillation. III: development of a definitive surgical procedure. J Thorac Cardiovasc Surg. 1991;101:569-83.

16. Cox JL. The surgical treatment of atrial fibrillation. IV: surgical technique. J Thorac Cardiovasc Surg. 1991;101:584-92.

17. Nashef SA, Roques F, Michel P, Gauducheau E, Lemeshow S, Salamon R. European system for cardiac operative risk evaluation (EuroSCORE). Eur J Cardiothorac Surg. 1999;16:9-13.

18. Nashef SA, Roques F, Sharples LD, Nilsson J, Smith C, Goldstone AR, et al. EuroSCORE II. Eur J Cardiothorac Surg. 2012;41:734-44; discussion 744-5.

19. Shahian DM, O'Brien SM, Filardo G, Ferraris VA, Haan CK, Rich JB, et al The Society of Thoracic Surgeons 2008 cardiac surgery risk models: part 1-coronary artery bypass grafting surgery. Ann Thorac Surg. 2009; 88(1 Suppl):S2-22.

20. Ad N, Henry L, Hunt S, Holmes SD. Impact of clinical presentation and surgeon experience on the decision to perform surgical ablation. Ann Thorac Surg. 2013; 96:763-8; discussion 768-9.

21. Cox JL. A brief overview of surgery for atrial fibrillation. Ann Cardiothorac Surg. 2014;3:80-8.

22. Viola N, Williams MR, Oz MC, Ad N. The technology in use for the surgical ablation of atrial fibrillation. Semin Thorac Cardiovasc Surg. 2002;14:198-205.

23. De Maat GE, Van Gelder IC, Rienstra M, Quast AF, Tan ES, Wiesfeld AC, et al. Surgical vs. transcatheter pulmonary vein isolation as first invasive treatment in patients with atrial fibrillation: a matched group comparison. Europace. 2014;16: 33-9.

24. Mei J, Ma N, Ding F, Chen Y, Jiang Z, Hu F, et al. Complete thoracoscopic ablation of the left atrium via the left chest for treatment of lone atrial fibrillation. J Thorac Cardiovasc Surg. 2014;147:242-6.

25. Lall SC, Melby SJ, Voeller RK, Zierer A, Bailey MS, Guthrie TJ, et al. The effect of ablation technology on surgical outcomes after the Cox-maze procedure: a propensity analysis. J Thorac Cardiovasc Surg. 2007;133:389-96.
26. Ad N, Henry L, Hunt S, Holmes SD. Do we increase the operative risk by adding the Cox maze III procedure to aortic valve replacement and coronary artery bypass surgery? J Thorac Cardiovasc Surg. 2012;143:936-44.

27. Lee R, McCarthy PM, Wang EC, Vaduganathan M, Kruse J, Malaisrie SC, et al. Midterm survival in patients treated for atrial fibrillation: a propensity-matched comparison to patients without a history of atrial fibrillation. J Thorac Cardiovasc Surg. 2012;143:1341-51; discussion 1350-1.

28. Ad N, Holmes SD, Massimiano PS, Pritchard G, Stone LE, Henry L. The effect of the Cox-maze procedure for atrial fibrillation concomitant to mitral and tricuspid valve surgery. J Thorac Cardiovasc Surg. 2013;146:1426-34; discussion 1434-5.

29. Gammie JS, Didolkar P, Krowsoski LS, Santos MJ, Toran AJ, Young CA, et al. Intermediate-term outcomes of surgical atrial fibrillation correction with the CryoMaze procedure. Ann Thorac Surg. 2009;87:1452-8; discussion 1458-9.

\section{Discussion}

Dr Richard Lee (St Louis, Mo). I have no disclosures. Dr Ad, this is an important contribution to the field. I have 2 questions that I will ask 1 at a time.

First, the freedom from AF that you reported was an impressive $95 \%$, which has been duplicated in some other single institution series. However, in the Concomitant Utilization of Radio Frequency Energy for Atrial Fibrillation trial and ABLATE-AF trial, the freedom from atrial fibrillation was $67 \%$ and $84 \%$, respectively, using the same lesion set as in your series at multiple centers and with multiple surgeons. How do you account for the superiority of your results and does this limit the generalizability of your prediction model to other centers?

Dr Ad. Well, Rick, thank you. There are many ways to answer this question. One of the only smart decisions I made regarding the surgical treatment of AF was basically to take what I learned in the past very seriously; I never changed it. Dr Jim Cox presented his concept $>25$ years ago, and I actually never moved away from it.

I believe that the only difference between our group and others is that we all perform the correct Maze lesion set using only tools with proven transmurality; these are not only my own results. I think if you do this, your success rate is going to be high.

Dr Lee. Second, in your report, you were kind enough to cite one of my studies that showed a survival advantage for patients surgically treated for AF. However, in that population, only those patients who were free from both AF and antiarrhythmic therapy at 1 year had improved survival, similar to the implications of the multivariable analysis of the Atrial Fibrillation Follow-up Investigation of Rhythm Management trial.

Please clarify why you did not use freedom from AF and antiarrhythmic agents as a primary endpoint and what needs to be done to establish a prediction model for this important variable?

Dr Ad. Well, that is an interesting question. Again, this is a first step, and I think it is an important step, where we can sit and talk with the patient and say, you know, this is the prediction of you being in SR. Whether SR without and with medication is the key, this is still an open question, and, despite the guidelines, some of us strongly disagree with this type of definition. However, being clearer, the model is still as accurate when you take the medication variable out, we just did not believe it was important to include here to avoid confusion. I think in the future when we have more collaboration and more patients, we will be able to also predict freedom from cardioversion and freedom from antiarrhythmic drugs. 
Mind you, we were persistent in the adherence to the HRS guidelines, such that any ablation was considered a failure.

Dr Vinay Badhwar (Pittsburgh, Pa). Niv, another wonderful contribution, and I think what is extremely important is that all our current scoring systems of the quality of cardiac surgery are currently focused on major morbidity and mortality outcomes, and this is one of the first that will be focusing on a no mortality and no morbidity procedural efficacy outcome.

I know from your past work that your lesion set has been consistent, as has been its energy source. As a part of your predictive model, just for clarification of us all, was this consistent throughout all patients and all surgeons performing the same lesion set with the same "tool," as you called it?

Dr Ad. I am not operating all the time, but the group, in general, I think is fairly educated about the lesion sets and how to apply them, and I believe that this is the key. Also, the energy sources being used were either cryothermia alone or a combination of bipolar radiofrequency and cryothermia, which previous publications, ours and others, showed no difference between them.

Dr Badhwar. On the basis of that answer, perhaps it would be wise to include the energy source and precise lesion set adherence before external validation. Do you think this would be a factor in the development of a scoring system?

Dr Ad. I think that it might be a good idea. I question whether it is going to add anything, because I predict that, at least in our model, it will not show any significance at 1 or 2 years whether you use bipolar and cryothermia or cryothermia alone, and Ralph is here and can comment on that. I think it is an excellent question. I just do not believe that, at least in our center, it will show any difference.

As for a lesion set, this is specifically a Cox maze III or IV, it depends on how you want to call it, lesion set in all patients, and that is crucial. I can go back and look, because, as you know, in our database it has been entered after every case whether there were deviations from the Cox maze procedure perceived by the surgeon, and, again, if so, it occurred in very few patients.

Dr A. Peter Kappetein (Rotterdam, The Netherlands). It is great, as Dr Badhwar pointed out, that you have developed an efficacy model instead of just a safety model. The AUC of 0.85 is impressive and very difficult to achieve in any other prediction model. You only had 525 patients to develop this model, and your success rate was pretty high for achieving SR.

So how many endpoints did you have? In other words, how many patients had AF during follow-up? Because these are the ones for which you want to try to find the predictive factors. That is a relatively small proportion.

In your abstract, you stated that a 1-cm increase in LA size resulted in a $2.3 \%$ reduction in the success rate. That means that if you have a success rate of $98 \%$, it will decrease to $95.7 \%$. How can it be so accurate, and do you assume that all variables have a linear relationship with the outcome? Because I can also imagine that if the LA size is greater than a certain threshold, treatment will not be so successful.

Dr Ad. I think that it is something we were surprised at. This obviously I consider one of our most important projects ever. I was fairly surprised, and we did check ourselves again and again and again, and these are indeed the data, and whoever knows us knows that this is really something we take a lot of pride in, our reliability in reporting results.

The LA size might be a little different in the prediction for failure compared with other centers, because more experienced surgeons were managing a larger atrial size. Also, we published a couple of months ago that 2 sizes are crucial in which we should pay attention for success, whether with or without medication, $5.5 \mathrm{~cm}$ and $7.5 \mathrm{~cm}$. However, even if you treat patients with a $>10-\mathrm{cm}$ left atrium, the success rate without medication at 2 years was $>50 \%$, but there are not many.

Dr Kappetein. So you assume still that you can use it as a continuous variable instead of as a categorical variable?

Dr Ad. Yes.

Dr Kappetein. How many patients actually did not achieve SR? In how many patients was treatment not successful?

Dr Ad. I do not remember off the top of my head, but, again, we classified failures in a few categories that can correlate with burden: 30 seconds to 5 minutes, 5 minutes to 1 hour, $>1$ hour, and continuous. But I do not remember it off the top of my head.

Dr Kappetein. Because that is a very important figure.

Dr Ad. Good point.

Dr Sary F. Aranki (Boston, Mass). I have a question regarding anticoagulation. How do you use your prediction model in managing anticoagulation in those patients and does the size of the left atrium have any effect on your management decision?

Dr Ad. First, the prediction model is not designed to answer whether the patient will require anticoagulation. What we do practically for anticoagulation is basically 3 months of postoperative antiarrhythmic drugs and anticoagulation, then we stop the antiarrhythmic drugs, and we monitor the patient-long-term monitoring, anywhere from 4.5 months to 6 months. When we see that they are basically not in AF based on this type of assessment and the echocardiogram shows that no smoke is present in the atrium and the LA appendage has been controlled, the recommendation to stop anticoagulation applies.

If smoke is present in the left atrium or the LA appendage is not well controlled and the patient has higher CHADS scores, we have some discussions around all of it. Our rate of stopping anticoagulation has been fairly high. One caveat is that in many cases it will be the decision of the cardiologist, and, despite our recommendation, the patient will continue with anticoagulation medication. However, theoretically, if you remove all the patients who do not require anticoagulation due to $\mathrm{AF}$ or other reasons, such as a mechanical valve or deep venous thrombosis, you can basically eliminate warfarin in $>85 \%$ of the patients after 6 months.

Dr Harold L. Lazar (Boston, Mass). I just have 1 final question. Using your scoring system, are there any patients for whom you would not perform a concomitant maze procedure because you think that it just would not work?

Dr Ad. No, for myself; however, in the group, I think it varies. We have shown in the past, in work that was published in the Annals, that attrition occurs in the implementation of the Cox maze procedure for patients with more risk factors and, especially, with a larger left atrium and long AF duration. However, personally, I think you can achieve much greater than a 50\% success rate over time in extremely complex cases if you do it in an appropriate way, so it is worth it. 